\title{
Mineralogical, Crystal Structure and Chemical Composition Characterization of Iraqi Natural Rich- Montmorillonite Mineral Clays
}

\author{
R. A. Buker \\ Department of Chemistry / College of Education \\ University of Mosul
}

Received

05 / 01 / 2011
Accepted

02 / 03 / 2011

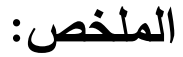

سوف تبين هذه الدراسة الخصائص المعدنية والتركيبية لرواسب من معادن طينية طبيعية

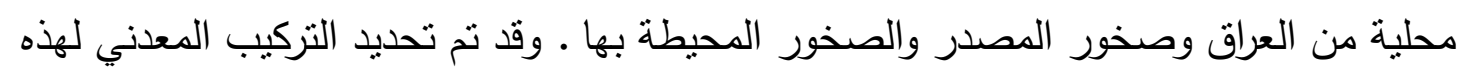
الرواسب الأولية لتشمل المونتموريلونايت، والكوارتز ، والجيبس، والكالسايت فضلا عن كميات

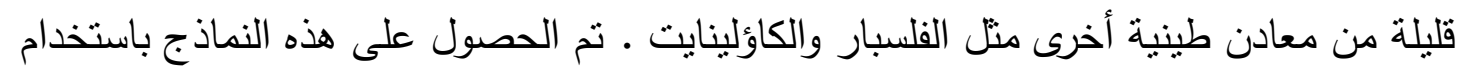
تقنيات حيود الأشعة السينية للمسحوق وفلورة الأشعة السينية والتحاليل الحرارية الوزنية والتفاضلية وطيف الأشعة تحت الحمراء فضلا عن آليات التحاليل الكيميائية التقليدية ـ ان الصفات الفيزيائية

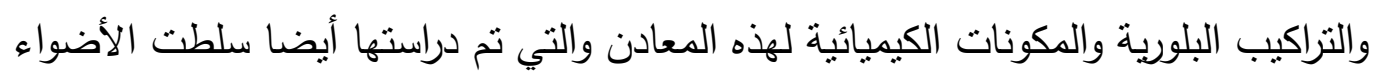

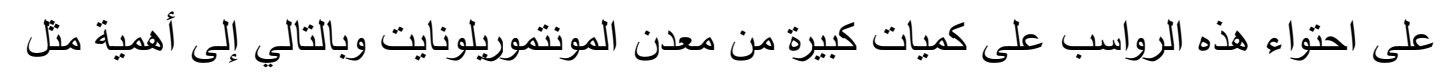
هذه الرواسب في الدجالات الصناعية.
\end{abstract}

\begin{abstract}
This study provides the mineralogical and compositional characterization locally natural mineral clay deposits of Iraq and their parent and enclosing rocks. The mineral assemblage of the raw clays of these primary deposits has been determined to include disordered montmorillonite, quartz, gypsum, calcite, in addition to trace amounts of other mineral clays like feldspar and kaolinite. Such results have been investigated using powder x-ray diffraction, x-ray fluorescence, thermo gravimetric analysis, differential thermal analysis, infrared spectroscopy, and technical chemical analysis. Physical properties, crystal structure, and, chemical composition of this montmorillonite rich mineral clays also have been performed to attribute that influence the industrial usage of Iraqi natural mineral clays are high lighted.
\end{abstract}




\section{Introduction:}

Supported catalysts represent the largest group of catalysts (heterogeneous) which are of major economic importance, especially in petroleum and petrochemical industries ${ }^{(1)}$. These catalysts are prepared by adding small amount of the active materials especially metal oxides to the surface of the porous solid support. The most important solid supports are alumina oxides, silica gel, $\mathrm{MgO}, \mathrm{TiO}_{2}, \mathrm{ZrO}_{2}$, aluminum silicates, zeolite, activated carbon and ceramics ${ }^{(2)}$. Fortunately such materials are occurred naturally in massive quantities in the world and especially around Mosul city/ Iraq ${ }^{(3)}$. Mineral clays are the interest material to deal with and the term clay implies a natural, earthy, fine-grained material which develops plasticity when mixed with limited amount of water. It is very stable during catalytic treatment processes. It has a surface endowed with weakly acidic and basic sites. The catalyst is able to maintain a high specific surface area up to about look, if transition metals ions are present $^{(4)}$.

Application of Iraqi raw minerals in petroleum refining was the interest of many workers, and recently, the natural Iraqi mineral clays have been investigated and applied in petroleum fractionation ${ }^{(5)}$.

Accordingly, and in continuation of investigating the chemical composition and structural properties of Iraqi raw materials, the present study is considered. It deal with montmorillonite - rich mineral clays naturally occurring around Mosul city/ Iraq.

\section{Experimental:}

\section{A- Sources and collections of samples:}

Natural minerals clay, obtained from area around Mosul city/ Iraq, were used as a natural clay samples. These samples were pale yellow in color have (120-150 mesh ASTM). Individual samples weighed from 1.0 to $3.0 \mathrm{~kg}$; and were thoroughly mixed before their coning and quartering to obtain representative samples. At each sampling site, parent rock, samples were also collected. For x-ray diffraction analysis and bulk mineralogy, the raw sample was powdered by agate mortar and agate tema mill.

\section{B- Methods of study:}

The identification of clay minerals and their alteration products was carried out by the power diffraction method, which carried out using Phillips $x$-ray diffraction equipment model pw/1710 with monochromator, Cu-radiation $\left(\lambda=1.54178 \mathrm{~A}^{\mathrm{o}}\right)$ at $40 \mathrm{k} . \mathrm{v}, 35 \mathrm{~m} . \mathrm{A}$. and scanning speed $0.02 \%$ sec. were used. The reflection peaks between $2 \theta$ $=2^{\circ}$ and $60^{\circ}$, corresponding spacing $\left(\mathrm{d}, \mathrm{A}^{\circ}\right)$ and relative intensities $\left(\mathrm{I} / \mathrm{I}^{\circ}\right)$ 
were obtained. The diffraction charts and relative intensities are obtained and compared with ICDD files. Meanwhile x-ray fluorescence spectrophotometer was employed for natural clays on Phillips / PW 2404 analysis and the absorption spectra were recorded on FTIR 4100 JASCO spectrophotometer using $\mathrm{KBr}$ disk ${ }^{(6)}$.

The thermal analysis was by means of Schimadzu DTA-50H, and TGA-50H. Each powdered sample was heated by $10^{\circ} \mathrm{C} / \mathrm{min}$. up to $1100^{\circ}$ $\mathrm{C}$ with $\alpha-\mathrm{Al}_{2} \mathrm{O}_{3}$ as a reference material. Temperature, weight change in wt., and the thermal behavior of the sample is recorded on the chart.

The above technical studies were performed at ministry of petroleum, the Egyptian mineral resources authority, central laboratory sector/ Egypt.

\section{Results \& Discussion:}

\section{A. Chemical analysis: -}

The results of chemical analysis provide information on the mineralogical composition of the samples, both on the amount of the primary mineral and on amount and nature of any other minerals present in the sample. However, such interpretation of the chemical analysis requires additional information, primarily crystallographic information from x-ray analysis. Further clues are provided by the results of dissolution experiments, thermal analysis and spectral analysis. Chemical analysis of the suite of clay samples were performed by means of x-ray fluorescence and traditional chemical analysis techniques, like atomic absorption spectra and flame photometry and shown in Table (1). It seems that natural samples compose of different oxides most of them related to mineral rocks and clays suggested to be used as absorbent catalysts like silica, alumina, iron oxide, calcium, magnesium and potassium oxides ${ }^{(7)}$.

\section{B. Physical properties: -}

Minerals rocks and clays should have certain physical properties in addition to their chemicals to be satisfactory adsorbent materials and used in industrial processes ${ }^{(8)}$. The major advantages of such uses are listed in terms of porosity, density, surface area, and water absorption. Accordingly, such physical properties for the studied sample are presented in Table(2). It seem that natural clay sample shows low density, low porosity, low permeability, low pore size and high surface area. In order to interpret such results, the capillary action was measured also and the rising water level observed in the clay sample as monitored with the time is taken as the measurement of the capillary action, Figure(1).

It seem from the data, which demonstrate the rapid rise of water in the first few minutes, that such sample consist of a large number of fine 
cavities well connected by extremely very narrow channels and hence allowing the water to more up easily through the clay sample ${ }^{(9)}$.

\section{Structural investigation: -}

The mineralogy of sedimentary clays and rocks and their related compounds may be determined on the bases of x-ray diffraction, x-ray fluorescence, dehydration characteristics, thermal analysis, infrared absorption ...... etc ${ }^{(10)}$. Many rock and clay materials are composed of more than one mineral, and the minerals may be mixed in several ways. It is well known that careful x-ray diffraction studies reveals the presence of mixed layer structures and frequently indicate the nature and the relative abundance of the units that are mixed.

Accordingly, such technique has been applied for the natural clay sample under investigation. Powder x-ray diffraction pattern of natural sample which is shown on Figure(2) reflects the presence of montmorillonite mineral in addition to quartz, gypsum and calcite minerals. Such mixed units of clay minerals identified by their clearly first highest peaks. Meanwhile, other trace minerals like feldspar and Kaolinite proposed to be present but through their minor reflection peaks ${ }^{(11)}$. Inter planar spacing of the above major mixed unites of clay minerals are presented in Table(3). Moreover, it is of interest that powder $\mathrm{x}$-ray diffraction might be used to calculate the percentage values of the above relative minerals ${ }^{(12)}$. From the calculated area under the highest peak of each mineral, it is clear that montmorillonite presents as $55 \%$ of the investigated clay sample. Meanwhile, other minerals appear to be 18 , $18,9 \%$ respectively.

It is obvious that rocks and clays are porous in character and should held water molecules as a hydration and geometrical water. Both TG \& DTA were used to determine the purity level and to help identify contaminants or impurities.TG analysis allowed quantitative estimation of the clay minerals present in the sample on the of - the - art methods ${ }^{(13)}$. Determination of loss on ignition (LOI) provided an approximate across check on the TG Figures. Therefore, TG \& DTA were employed to study the hydration phenomenon and the results were presented in Figures(3\&4). In general and in referring to the literature it appears that TG and endothermic DTA peaks at approximately $171^{\circ} \mathrm{C}$ correspond to the removal of $20 \%$ absorbed water in gypsum mineral which present in the investigated clays. Therefore, it looks to represent the hydration phenomenon of the present gypsum. It is obvious that there are two endothermic peaks related to montmorillonite mineral, the first one corresponds to absorbed water on the surface of the particles, the peak temperature lies at $187^{\circ} \mathrm{C}$. the second peak is the main peak and is associated with expulsion of the main form minerals, TG exhibited in the 
Figure(3). The weight loss due to hydroxylation at $743^{\circ} \mathrm{C}$ used to determine the amount of montmorillonite present (14). Pure montmorillonite losses approximately $4,47 \%$ provided that other minerals, which show weight loss in the same temperature may are absent. Moreover, TG \& DTA curve at approximately $915^{\circ} \mathrm{C}$ shown in the Figure $(3 \& 4)$, assigned to represent the transformation of calcite mineral to the oxide from through the weight loss of approximately $44 \%$ of the present calcite in the studied clays.

Finally, Figure (4) shows an endothermic peak which is sharp and occurs at temperature below $900^{\circ} \mathrm{C}$ and might be associated with the transformation of $\beta$-quartz to $\beta$-tridymite phase ${ }^{(9)}$.

The specific heat $\mathrm{Cp}$ of a material is defined as the amount of heat required to raise the temperature of a unit mass of the material by one degree Celsius. The specific heat is usually measured by the differential scanning calorimeter and also it could be identified by DTA via measuring the area under the specified curve and comparing such value with standard materials. Therefore, the following expression was used to determine the $\mathrm{Cp}: \mathrm{A}=\mathrm{C}$ p N $(-\Delta \mathrm{H}){ }^{(15)}$ where: $\mathrm{A}$ : the area under the curve, $\Delta \mathrm{H}$ : the enthalpy change, $\mathrm{N}$ : number of reactant moles, $\mathrm{C}^{\prime}:$ constant $=1090.71$ and the calculated specific heat result was: $7176 \mathrm{KJ} / \mathrm{kg} . \mathrm{k}$

Finally, it is of interest to investigate both, the migration and elimination of the held water molecules in addition to the mineralogy of the clay sample under investigation by infrared absorption technique. Therefore, a range of $400-4000 \mathrm{~cm}^{-1}$ in frequency was applied and the spectra revealed several absorption bands including those between 10001100 and $797-775 \mathrm{~cm}^{-1}$ which are attributed to the Si-O stretching and bending vibrations ${ }^{(6)}$. Moreover, the absorption band located at $467 \mathrm{~cm}^{-1}$ is definitely characteristic of Al-O absorption, whereas the absorption band at 1425 and $876 \mathrm{~cm}^{-1}$ are attributed to stretching and banding of $\mathrm{CO}_{3}$ group. Also there is absorption bands at $1630 \mathrm{~cm}^{-1}$ and in the range $3430-3640 \mathrm{~cm}^{-1}$ which are related to the structural $(\mathrm{OH})$ group. Such absorption shows a significance variance in the position and sharpness of the vibration up on heating the samples in the range of $120-600^{\circ} \mathrm{C}$, which is related to the dehydration phenomena ${ }^{(13)}$.

\section{Conclusions}

The mineralogical attributes of Iraqi natural mineral clay deposits studied by XRD, XRF, TG, DTA, IR and traditional chemical techniques corroborate the presence of platy disordered montmorillonite, quartz, gypsum, calcite and feldspar. There is general increase of montmorillonite minerals in some fractions as shown by TG analysis that gave content of 55\%. Such deposits appeared to be important for 
industrial uses, chemical bleaching may be required to remove the unwanted minerals in addition to the thermal activation.

\section{References}

1) J. Hagen, "Industrial Catalysis", $2^{\text {nd }}$ Ed., Wieley- VCH, Germany (2006).

2) F.S. stones, J. Mol. Cat., 59, 147(1990).

3) S. Z. Jassim and S.Q. AL - Naqib, J. Iraqi Geo. Sci., 22, 112 (1989).

4) G. Ertl, H.Knozinger, J. Weitkamp, "Handbook of Heterogeneous Catalysis". VCH, Weinheim (1997).

5) R. A. Buker and S.A.M. AL- Mallah, J. Educ. And Sci., 17(4), 42 (2006).

6) K. Nakamoto, "IR and Ramman Spectra of Inorganic Compounds" $5^{\text {th }}$. Ed. John and Wiley Sons., New York(1997).

7) K. A. Karrado, S. E. Yuchs, K. Song, and N. Thiyagaraja, "Heterogeneous Catalysts Based on Clays", pergamon press Ltd., Britain (1996).

8) A. Allen, M. Kerch, G. Lony, S. Krueyer and F. Cosanday, J. Mater. Res., 14(4), 144(1999).

9) R. A. Buker and N. H. Taher, Dirasat, 33B (2), 158(2006).

10) K. Corneilis, "Mineral Science", $22^{\text {nd }}$. Ed., John. Wiley and Sons., Inc., New York, (2003).

11) N. Johnson, "x-ray Diffraction for Geological Applications", Schimadzu Group Company (2000).

12) Joint Committee in Powder Diffraction Standards, (JCPDS), Powder Diffraction Files, Search Manual, USA (1976).

13) M. A. Siddiqui and Z. Ahmed, The Arabian J. Sci. and Eng., 30(2A), 195 (2005).

14) H. H. Murray, "Clays in Industries", Elsevier Sci. Pub., Amsterdam (2003).

15) O. M. Hamdoom, Ph.D. Thesis, Thermal Power Engineering, Mosul University, Iraq (2009).

Table(1): Chemical composition of natural clay sample

\begin{tabular}{|l|l|l|l|l|l|l|l|l|l|}
\hline$\% \mathrm{SiO}_{2}$ & $\% \mathrm{Al}_{2} \mathrm{O}_{3}$ & $\% \mathrm{MgO}$ & $\% \mathrm{CaO}$ & $\% \mathrm{Na}_{2} \mathrm{O}$ & $\% \mathrm{~K}_{2} \mathrm{O}$ & $\% \mathrm{Fe}_{2} \mathrm{O}_{3}$ & $\% \mathrm{TiO}_{2}$ & $\% \mathrm{SO}_{3}$ & $\mathrm{LOI}$ \\
\hline 64.45 & 9.32 & 5.86 & 11.19 & 1.73 & 0.41 & 0.42 & 0.09 & 1.20 & 5.33 \\
\hline
\end{tabular}

Table(2): Physical properties of natural clay sample

\begin{tabular}{|c|c|c|c|c|c|}
\hline $\begin{array}{c}\text { Density } \\
\mathrm{g} / \mathrm{cm}^{3}\end{array}$ & Porosity\% & $\begin{array}{c}\text { Surface area } \\
\mathrm{g} / \mathrm{cm}^{2}\end{array}$ & $\begin{array}{c}\text { Water } \\
\text { absorption } \%\end{array}$ & $\begin{array}{c}\text { Pore size } \\
\mathrm{cm}^{3} / \mathrm{g}\end{array}$ & $\begin{array}{c}\text { Surface water } \\
\text { absorption } \%\end{array}$ \\
\hline 2.08 & 250.62 & 180.26 & 117.12 & 6.50 & 9.58 \\
\hline
\end{tabular}


R. A. Buker

Table(3): Interplanar spacings for contributing phases in clay sample

\begin{tabular}{|l|l|l|l|l|l|}
\hline Crystalline phase & hkl & $2 \theta^{\circ}$ & d values $\left(\mathrm{A}^{\mathrm{O}}\right)$ & $\begin{array}{c}\text { peak width } \\
(1 / 22 \theta)\end{array}$ & $\begin{array}{l}\text { Peak int. } \\
(\text { counts })\end{array}$ \\
\hline Montmorillonite & 100 & 6.100 & 14.4770 & 0.480 & 586 \\
\hline Gypsum & 100 & 11.720 & 7.5445 & 0.080 & 199 \\
\hline Montmorillonite & 101 & 17.690 & 5.0096 & 0.960 & 19 \\
\hline Montmorillonite & 112 & 19.805 & 4.4791 & 0.280 & 237 \\
\hline Quartz, Gypsum & 100,021 & 20.830 & 4.2610 & 0.240 & 132 \\
\hline Montmorillonite & 103 & 25.315 & 3.5153 & 0.320 & 17 \\
\hline Quartz & 101 & 26.730 & 3.3323 & 0.100 & 207 \\
\hline Gypsum & 113 & 28.150 & 3.1674 & 0.640 & 28 \\
\hline Gypsum,Calcite & 113,104 & 29.195 & 3.0563 & 0.200 & 92 \\
\hline Montmorillonite & 104 & 29.520 & 3.0234 & 0.120 & 83 \\
\hline Gypsum & 002 & 31.175 & 2.8666 & 0.200 & 29 \\
\hline Montmorillonite & 101 & 33.460 & 2.6759 & 0.120 & 26 \\
\hline Montmorillonite & 116 & 34.895 & 2.5690 & 0.480 & 88 \\
\hline Quartz, calcite & 110,112 & 36.055 & 2.4890 & 0.080 & 79 \\
\hline Quartz, calcite & 102,113 & 39.535 & 2.2776 & 0.120 & 25 \\
\hline
\end{tabular}

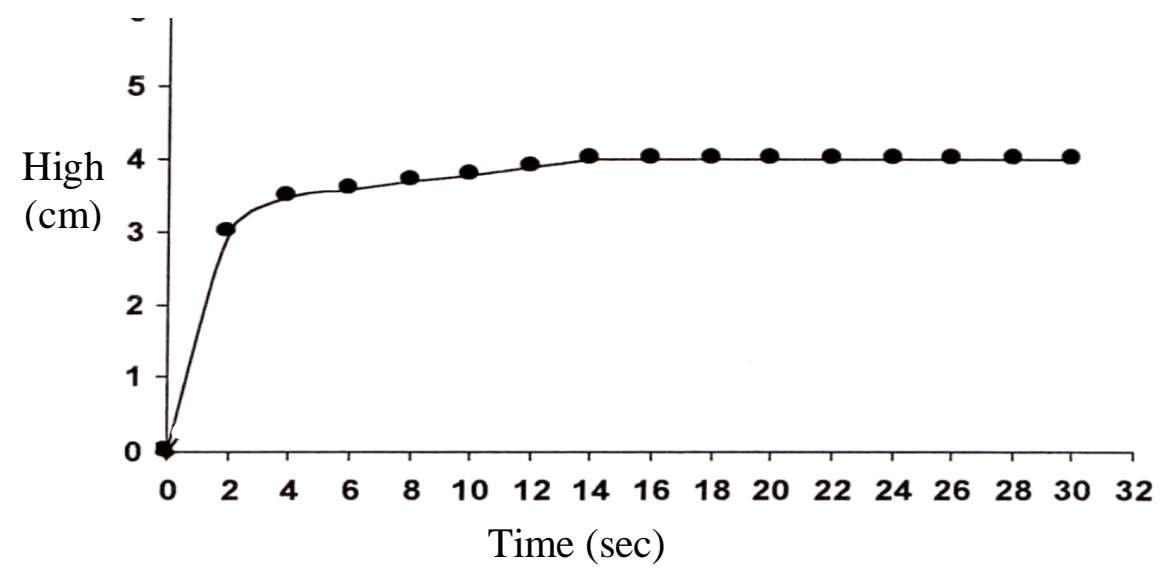

Fig 1: Capillary action curve of clay sample

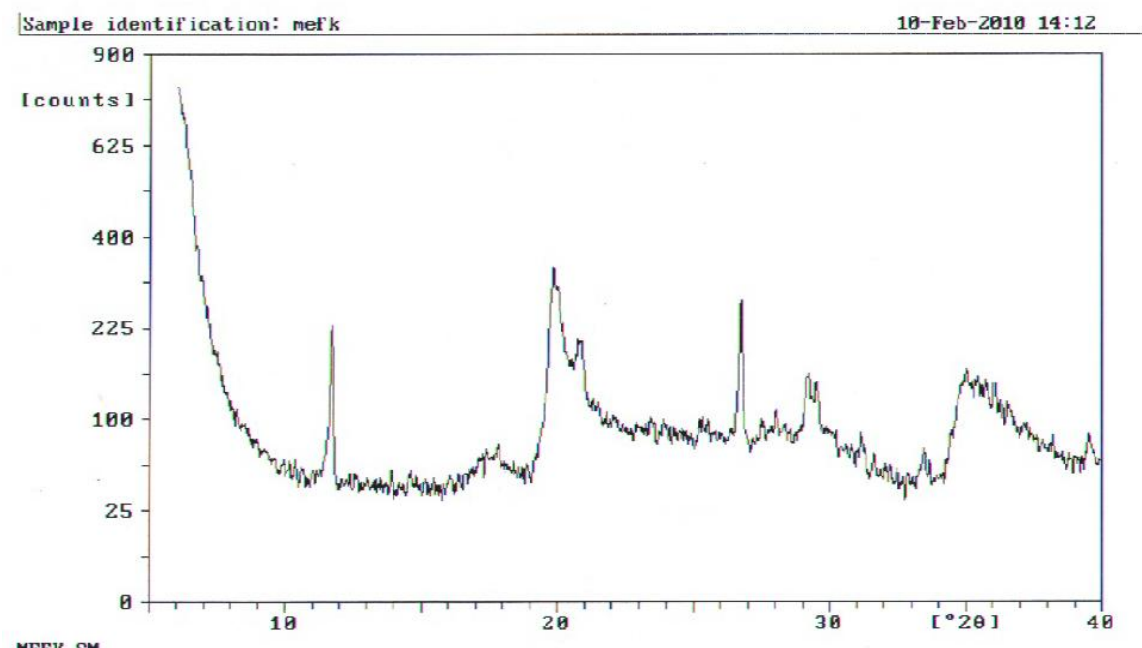

Fig 2: Powder X-ray diffraction pattern of clay sample 


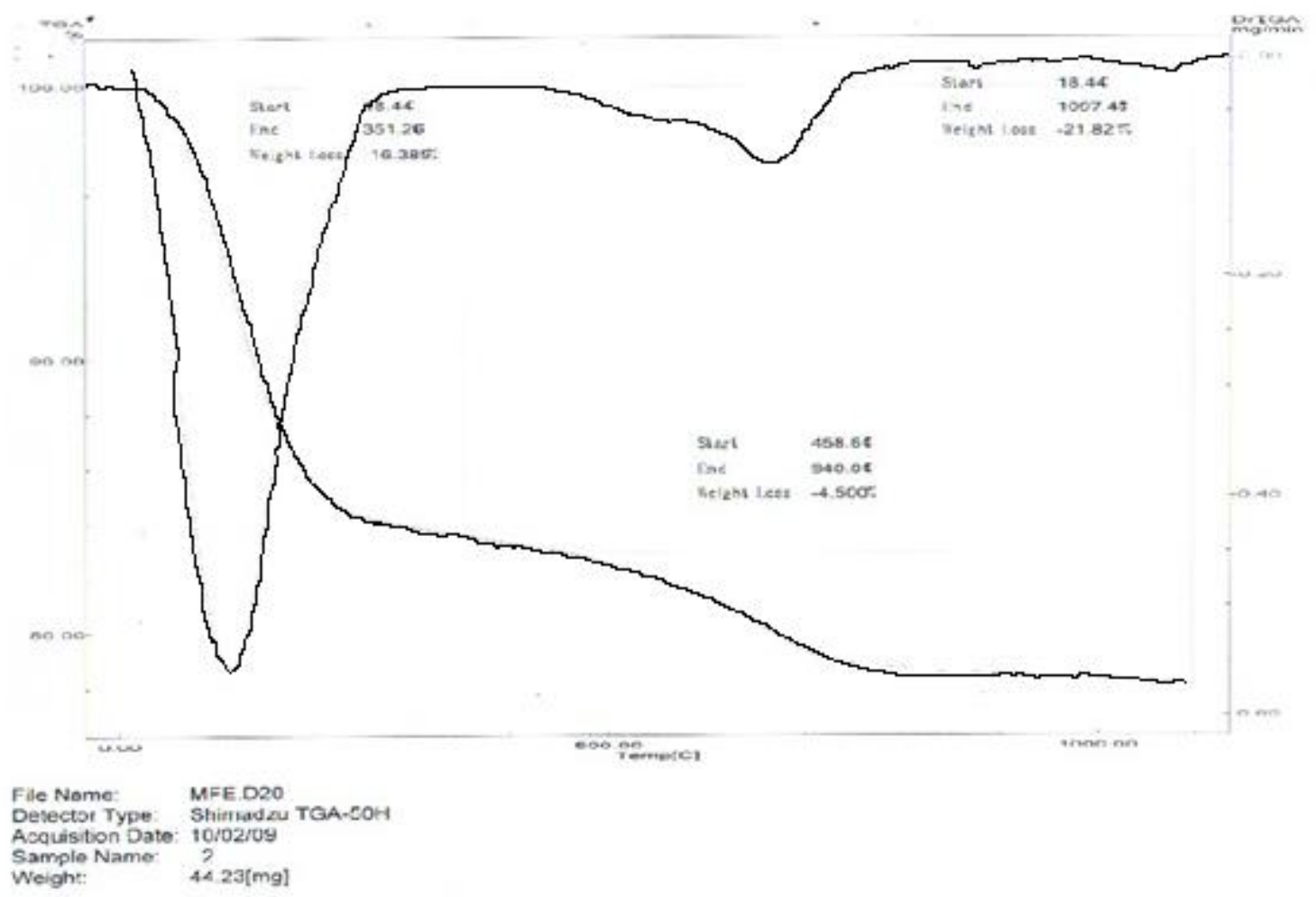

Fig 3: TG curves of clay sample

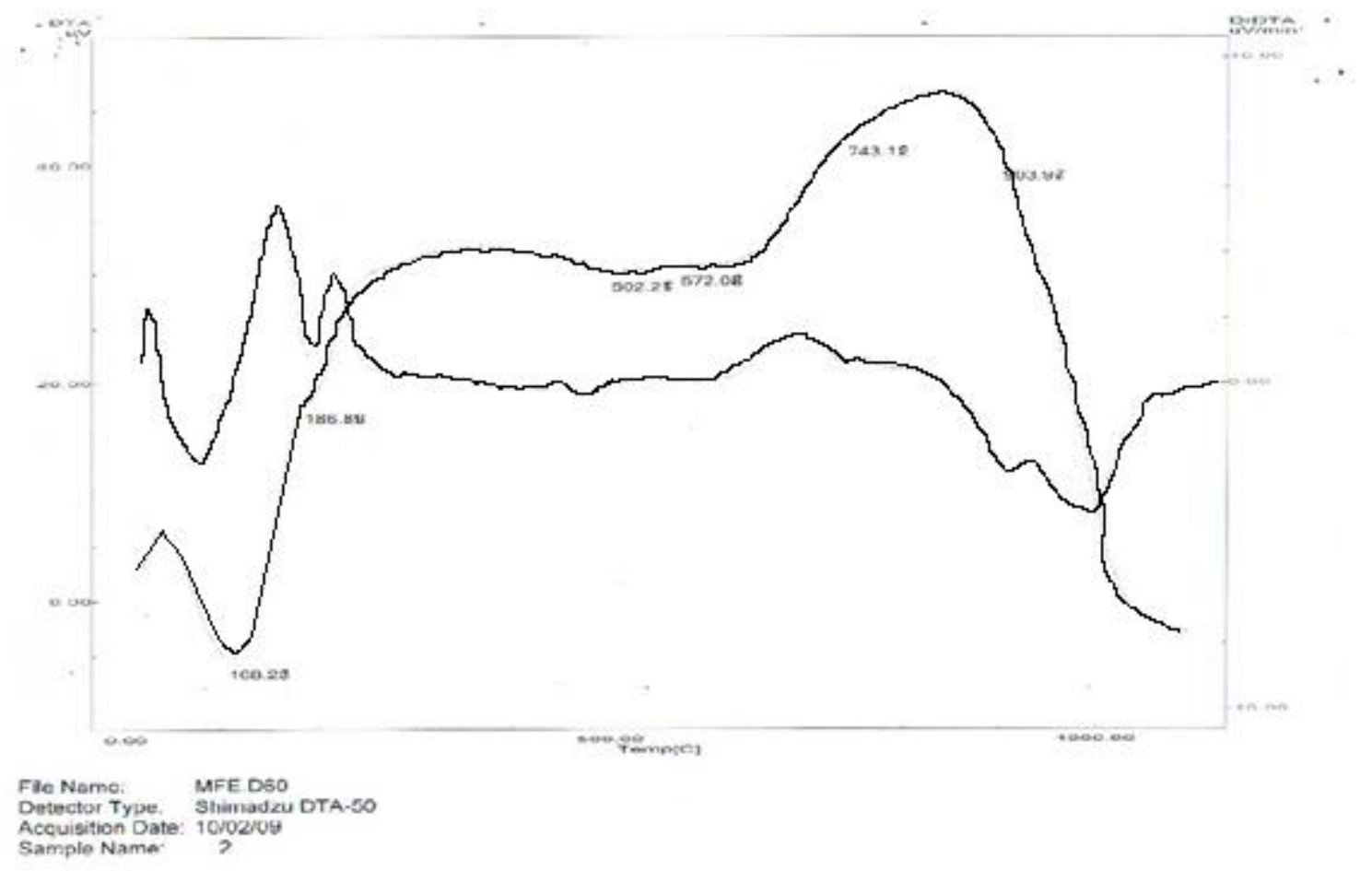

Fig 4: DTA curves of clay sample 